\title{
Construction and validation of a mentoring questionnaire based on Islamic culture
}

\author{
Morteza Khaghanizadeh ${ }^{1}$, Husein Taqavi ${ }^{1,2}$ and Abbas Ebadi ${ }^{1}$ \\ ${ }^{1}$ Behavioral Sciences Research Center, Life Style Institute, Baqiyatallah University of Medical Sciences, Tehran \\ and ${ }^{2}$ Faculty of Educational Sciences \& Psychology, University of Mohaghegh Ardabili, Ardabil, Iran
}

Education is considered to be a cultural and value-driven matter where any intervention in this field requires certain tools in order to describe the status quo. The current study, while taking into account the contextual texts related to Islamic mentoring, seeks to develop a tool to quantify this concept, as well as introduce the respective psychometric properties. A 113 items questionnaire was designed after reviewing the literature, the recommended guidelines concerning Islamic mentor and mentee, and reviewing available international tools. Content validity of the questionnaire was evaluated based on several criteria of clarity, fitness, and comprehensiveness by a survey of 10 experts and the necessary corrections were made. In the primary phase of this study, the psychometric properties of this questionnaire were evaluated by collecting the data from a random sample of 213 Iranian Ph.D. students in Tehran Universities of Medical Sciences. The factors analysis results show that 70 items, in the form of nine factors, construct the Islamic monitoring. Furthermore, The Cronbach's $\alpha$ coefficient was determined for each factor and the entire questionnaire. Total reliability of the scale was obtained at 0.97 . Considering the confirmed validity and reliability of the questionnaire, this tool can be highly beneficial for the experts and education professionals, particularly in the field of medicine, for the assessment and establishment of mentoring.

Key Words: Mentoring, Medical education, Iran

\section{Introduction}

The realization of individual, organizational-institutional, and social goals, defined for each educational system as well as overcoming possible challenges ultimately depend on cognitive, skill, and attitudinal development of learners; Furthermore, preparing competent professional agents, in addition to structure-based approaches such as formal academic programs, requires taking into account the social and interactive approaches, which Wenger [1] regards as the 'community of practice.' These formal procedures of preparation as such need people's interaction, leading to the formation of emergent learning systems.

Instead of immediate attention to professional development, these approaches concentrate on professional identity development; by using such structures as mentoring, they explain professional identity development. They also emphasize the fact that human learning occurs in interaction with others and observing and imitating them, social learning approach explains learners' development [2]. Mentoring represents one of such strategies for
Received: October 27, 2018 • Revised: January 26, 2019 • Accepted: March 25, 2019 Corresponding Author: Husein Taqavi (https://orcid.org/0000-0001-5943-8806) Faculty of Educational Sciences \& Psychology, University of Mohaghegh Ardabili, Ardabil, 56199-11367, Iran; Behavioral Sciences Research Center, Life Style Institute, Baqiyatallah University of Medical Sciences, Tehran, Iran

Tel: +98.9146238286 Fax: +98.4533520457 email: husen324@gmail.com
Korean J Med Educ 2019 Jun; 31(2): 159-172.

https://doi.org/10.3946/kjme.2019.127

eISSN: $2005-7288$

(C) The Korean Society of Medical Education. All rights reserved. This is an open-access article distributed under the terms of the Creative Commons Attribution Non-Commercial License (http:// creativecommons.org/licenses/by-nc/3.0/), which permits unrestricted non-commercial use, distribution, and reproduction in any medium, provided the original work is properly cited. 
development of competencies.

According to Kram [3] mentoring is defined as a dynamic relationship between younger and senior individuals that possesses the potential to enhance career and psychosocial development of both the mentor and the protégé. In the Kram [3] model, career functions and psychosocial functions are considered as the two major factors of mentoring which role modeling is considered as part of the second factor. While reviewing earlier studies, Johnson [4] divided mentors' capabilities into three main classes of cognitive, emotional, and relational abilities. In addition, skills or competency development, psychosocial or socio-emotional support, and career development are regarded as the other categories [5].

Reviewing the studies from 1983 indicates that reflection, coaching, counseling, assessment, role modeling, colleague/fellow learner, parenting mediating, making friend, and finally teaching can be considered as the most significant components of mentoring [6,7]. Furthermore, challenging, acceptance, confirmation, exposure and visibility $[3,8]$, interaction with the application of relational skills [4], and active listening [9] are other components which have been mentioned in a number of studies.

Numerous tools have been developed in order to assess these components. For instance, Noe [8] questionnaire with 29 items in the form of nine components, Fleming et al. [10] questionnaire with 26 items to measure six components, and the mentoring effectiveness questionnaire developed by Anderson et al. [11], which contains 18 items in order to measure five components, have all been credible questionnaires in this field.

Thus, the development of these tools highly suggests that different angles and aspects of mentoring have been largely clarified in various studies; however, given the dependency of research findings on the context, in particular, in education as a cultural matter, such find- ings cannot form the basis for making any decisions regarding educating professional agents, without taking into account the cultural conditions and environment. In addition, it should be noticed that the major aim of educational systems is to learn and nurture educated individuals. This issue is intertwined with the values of society [12].

Hence, due to the Islamic cultural principles and the current values associated with them in the Islamic countries, identification of mentoring components, as a developmental strategy in the medical field, seems necessary.

In addition to the cases mentioned previously, any intervention to higher education first and foremost, requires sufficient data to act as an observing tool in order to describe the status quo and consequently, plan for the desired situation and a questionnaire is considered as one of the efficient, inexpensive, and credible tools for obtaining this type of data. Therefore, the current study seeks to develop a tool to quantify and also introduce the associated psychometric properties in regard to contextual texts of Islamic mentoring and seek to determine the validity of the components of mentoring component extracted from Islamic texts.

\section{Methods}

A descriptive survey research method was utilized in this study and data were collected using Islamic mentoring questionnaire. The population of the study includes two groups of Ph.D. students in Baqiyatallah University of Medical Sciences and Tehran University of Medical Sciences (in the Islamic Republic of Iran); the required sample for collecting quantitative data was selected from students who already had a thesis. Stratified random sampling was used; because of the 
uncertainty of the study population number, In order to determine the sample volume, "the ratio of sample volume to the number of variables' method in factor analysis studies was employed (two to 10 cases for each variable), which the respective ratio is within the limits in this study.

Subsequently, 300 questionnaires were distributed among participants in this study, where the completion rate was at $85 \%$. At the next step, following the data screening, before and after data entry in the used software, 42 questionnaires were disregarded for the further proceedings. Finally, 213 completed questionnaires by students were then used for the final analysis. The Research Ethics Committee of Baqiyatallah University of Medical Sciences approved the study (IRB approval no., IR.BMSU.REC.1395.61). The demographic characteristics of participants are presented in Table 1.

Islamic mentoring questionnaire was used in order to collect data. Since the aim of the our study was to develop a tool for studying the mentoring based on Islamic culture, the literature regarding the Islamic mentor and mentee relations were initialy analyzed in order to investigate the features and properties of this type of mentoring. These studies consist of theoretical texts, conducted studies, practices, instructions, policies, and developed plans [13]. In order to extract the indicators of Islamic mentoring in the current study, Quran as well as Hadith by Imams referenced in Usul al-Kafi, Wasael Al-Shia, and Nahj al-Balaghah were investigated. Other reliable Islamic texts and research reports were investigated, which were obtained by studying first-hand references of educational approaches related to the Islam prophet, Imams, and Shiite clergyman. Other references which were evaluated include educational guidelines and methods proposed by prominent Islamic scholars and researchers. The procedure in which the content of these guidelines were investigated was as follows: (1) specifying related descriptors for mentoring and determining keywords; (2) specifying references, finding, and classifying them; (3) ranking Islamic texts, library articles, and conducted studies based on their importance; (4) analytical investigation of Islamic texts and preparing a summary and main points; (5) comparing and matching the proposed definitions and points and identifying the main properties and related details; (6) extracting codes and classifying them (more than 300 codes); (7) identifying the main categories (25 categories); and (8) developing themes while the identified categories are being integrated, encountered and their respective relations are being identified (nine themes).

Accordingly, in the current study, Islamic Mentoring refers to developmental relationships between supervisors as experienced individuals and students as an inexperienced individuals which status is determined on the basis of nine components that were extracted from Islamic texts and sources. The components of Islamic Mentoring, their definitions, and related items of the developed questionnaire were presented in Table 2 and Appendices 1, 2.

\begin{tabular}{|c|c|c|c|c|c|c|}
\hline \multirow{2}{*}{ Medical selected universities } & \multirow{2}{*}{ Total } & \multicolumn{2}{|c|}{ Gender } & \multicolumn{3}{|c|}{ Age (yr) } \\
\hline & & Male & Female & $<28$ & $28-33$ & $>33$ \\
\hline Tehran University of Medical Sciences & $157(73.7)$ & $37(25)$ & $111(75)$ & $15(10.3)$ & $62(42.8)$ & $68(46.9)$ \\
\hline Baqiyatallah University of Medical Sciences & 56 (26.3) & $25(44.6)$ & $31(55.4)$ & $2|3.6|$ & $24(42.9)$ & $30(53.6)$ \\
\hline Total & 213 & 62 & 142 & 17 & 86 & 98 \\
\hline Missing & 0 & 9 & & 12 & & \\
\hline
\end{tabular}

Data are presented as number (\%). 
Table 2. Islamic Mentoring Components Definitions and Related Items

\begin{tabular}{|c|c|c|}
\hline Component & Definition & Related items \\
\hline Role modeling & $\begin{array}{l}\text { It refers to the process of observing, being impressed by, and imitating a developed, reputable, eligible, } \\
\text { and trusted person. A role model is a person that is imitated and followed. A student's perception } \\
\text { of the professor's professional capacity, authenticity li.e., the extent of keeping promises and matching } \\
\text { words and actionsl, and fairtreatment of the students, respect for the professor, submission to } \\
\text { the professor's values and opinions, and acceptance of the professor's scientific authority are indicative } \\
\text { of role modeling. }\end{array}$ & $\begin{array}{l}1-3-4-5-6-36- \\
37-38-39\end{array}$ \\
\hline Challenging & $\begin{array}{l}\text { It refers to the statement of problems and assignment of difficult feasible tasks with the aim of } \\
\text { unearthing the students'talents and competencies, identifying the place of each problem as a whole, } \\
\text { and understanding the sophistication, complexities, and depth of the events. }\end{array}$ & $\begin{array}{l}2-7-8-9-10-11 \\
-12-26-27\end{array}$ \\
\hline Coaching & $\begin{array}{l}\text { It refers to the act of showing the path and the procedure. This component refers to a set of regular, } \\
\text { continuous, and committed activities performed by providing certain information and instructions. } \\
\text { Coaching is characterized by the act of showing how activities are performed, providing scientific } \\
\text { instructions, extending scientific generosity, assigning continuous tasks, and organizing and providing } \\
\text { feedback for adequately improving the knowledge and skills of the students. }\end{array}$ & $\begin{array}{l}13-14-15-16- \\
17-18-19-20 \\
-40-62-83- \\
84\end{array}$ \\
\hline Encouragement & $\begin{array}{l}\text { It refers to a set of practical and verbal actions taken to motivate the students for growth and development } \\
\text { by appreciating and distinguishing the top students and rewarding them proportionally. }\end{array}$ & $\begin{array}{l}25-77-78-79- \\
80-81\end{array}$ \\
\hline Counseling & $\begin{array}{l}\text { It refers to the extent of interactions established by trusting, sympathizing with, and accepting the } \\
\text { students. Such interactions serve to help the students understand their emotions, characteristics, } \\
\text { and positions and make effective decisions. }\end{array}$ & $\begin{array}{l}28-47-48-49- \\
50-56-57-55 \\
-85\end{array}$ \\
\hline Protection & $\begin{array}{l}\text { It refers to extent of protecting the person from the problems and dangers by showing benevolence, } \\
\text { finding solutions to personal, administrative, and professional problems, and being available especially } \\
\text { at times of crisis that jeopardize the student's current position and professional future. To wit, it } \\
\text { refers to the act of helping the student feel he/she can seek refuge from the risks posed by the } \\
\text { environment, others, and their actions in the professor. }\end{array}$ & $\begin{array}{l}51-52-53-54- \\
66-67\end{array}$ \\
\hline Care \& reverence & $\begin{array}{l}\text { It refers to the recognition of the perceptions, opinions, traits, and personal growth of the students } \\
\text { in the course of scientific and personal interactions and teaching. Gaining an accurate understanding } \\
\text { of the students through close interactions, continuous interactions, and intimacy, allowing the students } \\
\text { to express and implement their opinions and ideas, and fostering individuality and independence } \\
\text { are complementary to the perceiving behaviors. }\end{array}$ & $\begin{array}{l}21-22-23-24- \\
29-30-46-72 \\
-73-74-75- \\
76-82\end{array}$ \\
\hline $\begin{array}{l}\text { Good behavior } \\
\text { and facilitating }\end{array}$ & $\begin{array}{l}\text { Good temper refers to friendliness, perceiving behavior, politeness, and dignity in action and speech, } \\
\text { interaction, and avoidance of quarrels that hurt the feelings of the students. fairtreatment and tolerance } \\
\text { constitute the other side of this component, which refer to the ability to be patient, avoid the } \\
\text { development of stress in the students, avoid the development of anxiety in the students, and enable } \\
\text { the students to feel peaceful and calm in their interactions with the professor. }\end{array}$ & $\begin{array}{l}31-32-33-34- \\
35-58-59-60 \\
-61-63-64- \\
65-68-69-70 \\
-71\end{array}$ \\
\hline $\begin{array}{l}\text { Scientific } \\
\text { networking }\end{array}$ & $\begin{array}{l}\text { Setting the scene for collaboration with others and developing relationships with professionals with } \\
\text { the aim of enabling the person to access other role models, involving the person in the professional } \\
\text { community, and paving the person's professional career. }\end{array}$ & $\begin{array}{l}41-42-43-44- \\
45\end{array}$ \\
\hline
\end{tabular}

After the themes were extracted and the related characteristics and details were identified, the concepts and features, which acted as the indicators and were extracted as the primary codes in the previous section, were divided into measurable concepts. Then, multiple clauses were developed for each of them, which finally converted into questionnaire items. (1) Preparing question bank: At first three to six items were designed with regard to the identified characteristics for mentoring in Islamic texts and conducted studies as well as developed questionnaires. (2) Scoring system and preparing the necessary instructions: While reviewing the previous questionnaires, the proposed instruction by Hooman [14] was referred in order to determine the system of scoring; as a result multiple choice system were selected based on the Likert scale (from always to never) were selected. 
Two letters and instructions were developed; for the content validity evaluators and final respondents of the questionnaire, respectively. (3) Evaluating the content and factor validity of designed questionnaire: In order to ensure the content validity, clarity, and fitness of each item in the questionnaire and comprehensiveness of the entire questionnaire was initially examined, where experts assigned a score of 1 to 4 to each item in terms of clarity and fitness. The comprehensiveness of the entire questionnaire was also measured by a two-choice question. Furthermore, according to the Lynn [15] recommendations with respect to the diversity and number of experts, the required data in this field were collected from three groups of statistics and measuring experts (three individuals), education experts (three individuals), and Islamic teaching and education (four individuals). (4) Lawshe [16] criterion was employed in order to make decisions with respect to keeping, modifying or eliminating the items. A consensus of $62 \%$ by the experts was considered as the minimum acceptable value for the item to be remained in the questionnaire. In such a way that if $62 \%$ of the experts evaluated each item acceptable in terms of fitness and clarity, the item was considered valid. (5) Factor validity, as a form of construct validity, was assessed to evaluate the validity of the questionnaire. After screening and replacing the missing values, the obtained data of 213 participators were assessed using confirmatory factor analysis.

\section{Results}

After completing the forms of content validity assessment of the 113-item questionnaire, their validity was evaluated with respect to the acceptable values [16]. Therefore the items, which have been given score 3 or 4 by at least $62 \%$ of experts in regard to their 'relevance' and 'clarity,' remained intact and the rest of them were eliminated. Consequently 28 items out were eliminated out of the initially available 113. In addition, the items which were given a score 3 by experts for their relevance and clarity, were edited and modified once again. Moreover, the questionnaire comprehensiveness was also measured through yes or no response to these questions: (1) Do you think the questionnaire is comprehensive? and (2) Do you think the total number of items is adequate?

All 10 experts assessed that the questionnaire is comprehensive and the total number of items is adequate. The significance of the correlation matrix was checked prior to conducting the factor analysis. In addition, the Kaiser-Meyer-Olkin (KMO) Measure of Sampling adequacy was performed to analyze the feasibility of factor analysis and was determined at 0.941 . The results of Bartlett's test of sphericity also indicated that enough significant correlation exists between the items $(\bar{\chi}=$ $12,185.004$, degree of freedom $[\mathrm{df}]=2,415$, and $\mathrm{p}<0.001$ ). Therefore, due to the results obtained from the KMO test and Bartlett's test, data correlation was considered appropriate for the factor analysis.

Additionally, the correlation of all components with respect to the entire scale was calculated to meet the other condition of factor analysis, i.e., the rate of components communality with the main factor, which revealed that the minimum obtained correlation is 0.53 . Moreover, the correlation between each component is significant yet incomplete, which indicated the independence of mentoring developing factors (Table 3).

The initial factors were extracted in the second phase of factor analysis. In addition, first order confirmatory factor analysis was conducted using LISREL (Scientific Software International Inc., Lincolnwood, USA) in order to evaluate 85 items of Islamic mentoring questionnaire, which nine main factors can be achieved. Table 4 shows 
Table 3. The Correlation Coefficient of Mentoring Questionnaire with Subscales

\begin{tabular}{lcccccccccc}
\hline \multicolumn{1}{c}{$\begin{array}{c}\text { Islamic Mentoring } \\
\text { Questionnaire }\end{array}$} & 1 & 2 & 3 & 4 & 5 & 6 & 7 & 8 & 9 & 10 \\
\hline Role modeling & $0.794^{* *}$ & & & & & & & & \\
Challenging & $0.820^{* *}$ & $0.672^{* *}$ & & & & & & & \\
Coaching & $0.910^{* *}$ & $0.711^{* *}$ & $0.808^{* *}$ & & & & & & \\
Encouragement & $0.876^{* *}$ & $0.614^{* *}$ & $0.689^{* *}$ & $0.764^{* *}$ & & & & & \\
Counseling & $0.863^{* *}$ & $0.591^{* *}$ & $0.582^{* *}$ & $0.707^{* *}$ & $0.760^{* *}$ & & & & \\
Protecting & $0.833^{* *}$ & $0.542^{* *}$ & $0.599^{* *}$ & $0.680^{* *}$ & $0.762^{* *}$ & $0.788^{* *}$ & & & & \\
Care \& reverence & $0.901^{* *}$ & $0.665^{* *}$ & $0.688^{* *}$ & $0.778^{* *}$ & $0.795^{* *}$ & $0.735^{* *}$ & $0.780^{* *}$ & & \\
Facilitating & $0.742^{* *}$ & $0.665^{* *}$ & $0.409^{* *}$ & $0.560^{* *}$ & $0.593^{* *}$ & $0.683^{* *}$ & $0.592^{* *}$ & $0.657^{* *}$ & \\
Scientific networking & $0.838^{* *}$ & $0.596^{* *}$ & $0.683^{* *}$ & $0.761^{* *}$ & $0.684^{* *}$ & $0.730^{* *}$ & $0.670^{* *}$ & $0.734^{* *}$ & $0.539^{* *}$ \\
\hline
\end{tabular}

${ }^{* *}$ Significant at the $p<0.01$ level.

Table 4. Standardized Factor Loads, Determination Coefficient and t-Statistic (N=213)

\begin{tabular}{|c|c|c|c|c|}
\hline Item & Mean \pm standard deviation & $\mathrm{Fl}$ & $R^{2}$ & t-value \\
\hline 1 & $4.15 \pm 0.78$ & 0.44 & 0.59 & 4.5 \\
\hline 2 & $3.61 \pm 1.14$ & 0.53 & 0.44 & 5.5 \\
\hline 3 & $4.05 \pm 0.93$ & 0.31 & 0.75 & 3.3 \\
\hline 4 & $3.95 \pm 0.99$ & 0.69 & 0.52 & 8.5 \\
\hline 5 & $4.47 \pm 0.79$ & 0.32 & 0.57 & 3.9 \\
\hline 6 & $3.21 \pm 1.13$ & Removed & & \\
\hline 7 & $3.47 \pm 1.05$ & Removed & & \\
\hline 8 & $3.66 \pm 1.03$ & 0.50 & 0.88 & 6.5 \\
\hline 9 & $3.78 \pm 1.06$ & 0.40 & 0.82 & 3.5 \\
\hline 10 & $3.65 \pm 1.15$ & 0.30 & 0.86 & 3.1 \\
\hline 11 & $3.52 \pm 1.10$ & 0.27 & 0.93 & 2.9 \\
\hline 12 & $3.48 \pm 1.16$ & 0.64 & 0.83 & 5.5 \\
\hline 13 & $3.53 \pm 1.16$ & 0.37 & 0.92 & 3.5 \\
\hline 14 & $3.60 \pm 1.13$ & 0.28 & 1 & 2.5 \\
\hline 15 & $3.78 \pm 1.08$ & 0.30 & 1 & 3.1 \\
\hline 16 & $3.83 \pm 0.99$ & 0.43 & 0.91 & 4.7 \\
\hline 17 & $3.53 \pm 1.15$ & 0.43 & 0.84 & 4.7 \\
\hline 18 & $3.51 \pm 1.10$ & 0.45 & 0.72 & 4.9 \\
\hline 19 & $3.30 \pm 1.23$ & 0.44 & 0.95 & 4.8 \\
\hline 20 & $3.31 \pm 1.22$ & 0.46 & 0.87 & 4.9 \\
\hline 21 & $3.64 \pm 1.12$ & 0.72 & 0.44 & 7.8 \\
\hline 22 & $3.64 \pm 1.07$ & 0.32 & 1 & 3.5 \\
\hline 23 & $3.41 \pm 1.14$ & 0.39 & 0.91 & 4.1 \\
\hline 24 & $3.54 \pm 1.07$ & Removed & & \\
\hline 25 & $3.88 \pm 1.04$ & 0.73 & 0.65 & 7.1 \\
\hline 26 & $3.85 \pm 0.99$ & 0.81 & 0.71 & 8.5 \\
\hline 27 & $3.59 \pm 0.97$ & 0.50 & 0.80 & 6.7 \\
\hline 28 & $3.71 \pm 1.33$ & 0.56 & 0.72 & 6.9 \\
\hline 29 & $3.68 \pm 0.99$ & 0.31 & 0.44 & 3.2 \\
\hline 30 & $3.84 \pm 0.98$ & 0.38 & 0.44 & 3.9 \\
\hline 31 & $3.18 \pm 1.15$ & Removed & & \\
\hline 32 & $3.89 \pm 0.93$ & Removed & & \\
\hline 33 & $3.92 \pm 0.92$ & 0.64 & 0.88 & 5.4 \\
\hline 34 & $3.97 \pm 1.0$ & 0.52 & 0.69 & 4.8 \\
\hline
\end{tabular}




\begin{tabular}{|c|c|c|c|c|}
\hline Item & Mean \pm standard deviation & $\mathrm{Fl}$ & $\mathrm{R}^{2}$ & t-value \\
\hline 35 & $3.93 \pm 1.02$ & 0.33 & 0.86 & 3.1 \\
\hline 36 & $3.74 \pm 1.09$ & 1 & 1 & 11.5 \\
\hline 37 & $3.68 \pm 1.04$ & 0.37 & 0.72 & 3.3 \\
\hline 38 & $4.03 \pm 1.10$ & 0.32 & 0.73 & 3.1 \\
\hline 39 & $3.67 \pm 1.18$ & 0.30 & 0.85 & 2.9 \\
\hline 40 & $4.25 \pm 0.96$ & Removed & & \\
\hline 41 & $3.72 \pm 1.04$ & 0.42 & 0.80 & 4.5 \\
\hline 42 & $3.96 \pm 1.05$ & 0.44 & 0.87 & 4.6 \\
\hline 43 & $4.01 \pm 0.97$ & 0.32 & 0.88 & 4.1 \\
\hline 44 & $3.88 \pm 1.01$ & 0.41 & 0.89 & 4.7 \\
\hline 45 & $3.89 \pm 1.04$ & 0.54 & 0.93 & 5.5 \\
\hline 46 & $3.54 \pm 1.21$ & 0.40 & 0.66 & 4.5 \\
\hline 47 & $3.98 \pm 0.96$ & 0.49 & 0.77 & 4.9 \\
\hline 48 & $3.77 \pm 0.98$ & 0.31 & 0.88 & 3.1 \\
\hline 49 & $3.78 \pm 0.98$ & 0.34 & 0.79 & 3.2 \\
\hline 50 & $3.80 \pm 1.03$ & 0.50 & 0.72 & 4.5 \\
\hline 51 & $4.29 \pm 0.93$ & 0.42 & 0.82 & 4.1 \\
\hline 52 & $4.21 \pm 0.83$ & 0.65 & 0.90 & 6.5 \\
\hline 53 & $3.65 \pm 0.99$ & Removed & & \\
\hline 54 & $4.09 \pm 1.15$ & 0.58 & 0.58 & 5.5 \\
\hline 55 & $3.77 \pm 1.03$ & 0.62 & 0.61 & 6.1 \\
\hline 56 & $3.63 \pm 1.05$ & 0.35 & 0.80 & 4.5 \\
\hline 57 & $3.38 \pm 1.21$ & 0.33 & 0.85 & 4.1 \\
\hline 58 & $4.46 \pm 1.02$ & 0.34 & 0.74 & 4.1 \\
\hline 59 & $3.81 \pm 1.06$ & Removed & & \\
\hline 60 & $3.82 \pm 0.92$ & 0.28 & 0.65 & 2.9 \\
\hline 61 & $3.84 \pm 1.01$ & Removed & & \\
\hline 62 & $3.71 \pm 1.02$ & 0.46 & 0.72 & 4.5 \\
\hline 63 & $3.54 \pm 1.10$ & Removed & & \\
\hline 64 & $3.72 \pm 1.16$ & 0.54 & 0.71 & 5.1 \\
\hline 65 & $3.44 \pm 1.09$ & 0.85 & 0.47 & 9.5 \\
\hline 66 & $3.67 \pm 1.06$ & 0.65 & 0.88 & 6.3 \\
\hline 67 & $3.69 \pm 1.11$ & 0.40 & 1 & 4.1 \\
\hline 68 & $3.74 \pm 1.08$ & 0.84 & 0.47 & 8.1 \\
\hline 69 & $3.23 \pm 1.28$ & Removed & & \\
\hline 70 & $3.64 \pm 1.12$ & 0.80 & 0.59 & 7.7 \\
\hline 71 & $4.15 \pm 0.78$ & Removed & & \\
\hline 72 & $3.61 \pm 1.13$ & 0.32 & 0.73 & 3.1 \\
\hline 73 & $4.05 \pm 0.93$ & 0.51 & 0.89 & 4.7 \\
\hline 74 & $3.95 \pm 0.99$ & 0.38 & 0.90 & 3.7 \\
\hline 75 & $4.47 \pm 0.79$ & Removed & & \\
\hline 76 & $3.21 \pm 1.14$ & Removed & & \\
\hline 77 & $3.47 \pm 1.05$ & 0.36 & 0.93 & 4.1 \\
\hline 78 & $3.66 \pm 1.03$ & 0.51 & 0.92 & 59.5 \\
\hline 79 & $3.78 \pm 1.06$ & 0.36 & 0.91 & 3.4 \\
\hline 80 & $3.65 \pm 1.15$ & 0.32 & 0.90 & 3.1 \\
\hline 81 & $3.52 \pm 1.10$ & 0.41 & 0.91 & 4.1 \\
\hline 82 & $3.48 \pm 1.16$ & Removed & & \\
\hline 83 & $3.53 \pm 1.15$ & 0.50 & 0.83 & 4.5 \\
\hline 84 & $3.60 \pm 1.13$ & 0.91 & 0.86 & 10.4 \\
\hline 85 & $3.78 \pm 1.08$ & 0.89 & 0.76 & 8.9 \\
\hline Mean & 3.74 & & & \\
\hline
\end{tabular}


Fig. 1. Factor Analysis of Islamic Mentoring Questionnaire and Assessing Goodness of Fit

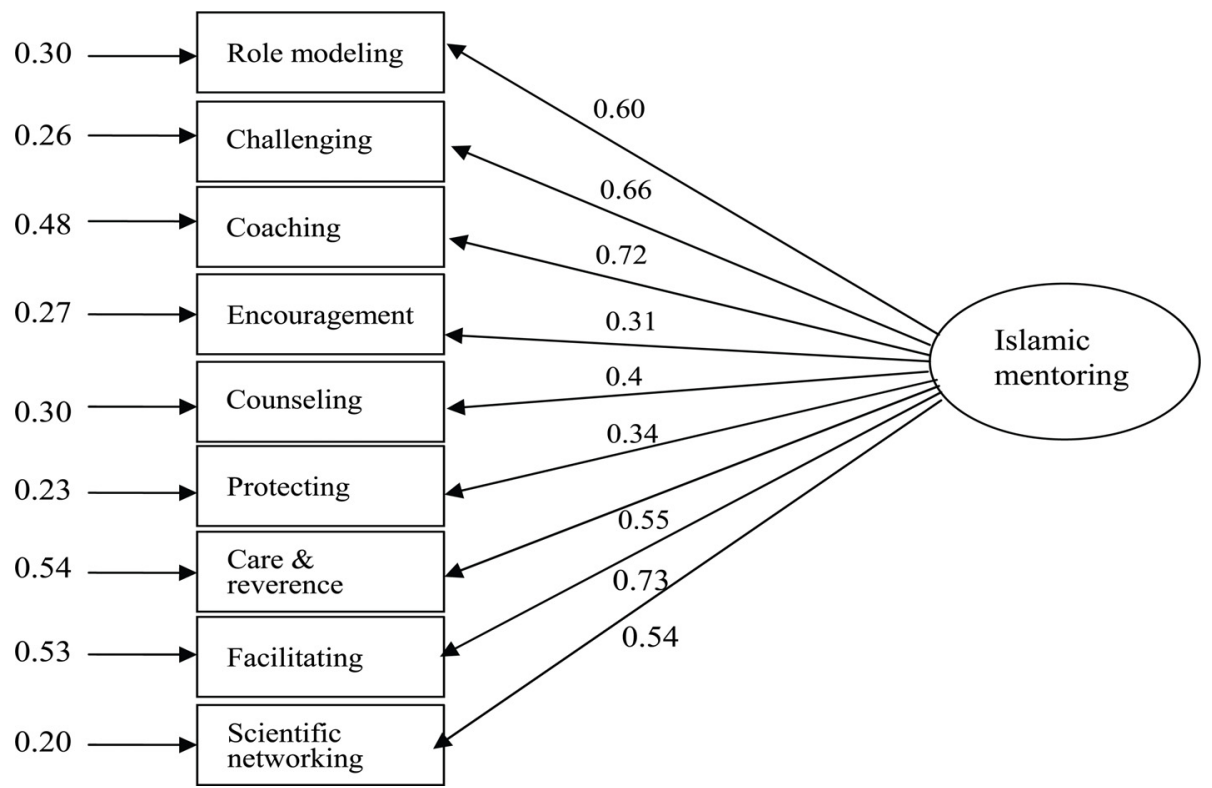

Chi-square $=1,660.17, \mathrm{p}<0.05, \mathrm{GFI}=0.96$, adjusted $\mathrm{GFI}, 0.95$, root mean square error of approximation $=0.057$.

GFI: Goodness-of-fit index.

standardized parameters of factor loads and determination coefficients and $t$-values.

As shown in Table 4, except in 15 items, estimation of standardized parameters of factor loads, determination coefficients, and $\mathrm{t}$-values indicate that the rest of model parameters were all significant and a considerable amount of variance was estimated (the value of $\mathrm{R}^{2}$ within 0.44 to 1 ). To confirm whether proposed subscales (or categories) form the emerged themes or not, secondorder confirmatory factor analysis was used.

Fitness indexes are shown in Fig. 1. The chi-square index in samples larger than 100 is often significant. Therefore, it may not be the most appropriate index for assessing model fitness in this study. A successful fitness can be achieved if the ratio of chi-square index to the df is less than 3. In addition, if the indexes of goodnessof-fit index (GFI), adjusted GFI, and comparative fit index are larger than 0.95 and root mean square error of approximation is less than 0.08 , a desired and proper fitness can be obtained.

The obtained values for the mentioned indexes show totally good fitness of data with the model. To estimate the reliability of questionnaire, internal consistency method, from Cronbach's $\alpha$ coefficient was used. The reliability coefficient in this study for whole test and subscales was acceptable. The obtained coefficients for the components were as follows: (1) role modeling with eight items at 0.79 , (2) challenging with eight items at 0.90, (3) coaching with 11 items at 0.94, (4) encouraging with six items at $0.91,(5)$ consulting with nine items at 0.89 , (6) protection with five items at 0.89 , (7) care and reverence with nine items at 0.88 , (8) good behavior and facilitating with nine items at 0.813 , and (9) scientific networking with five items at 0.894 . Finally, Cronbach's $\alpha$ coefficient for the entire questionnaire was also obtained as 0.97 .

\section{Discussion}

Mentoring is basically performed to assist and develop the students. Mentoring is expected to provide psy- 
chological and scientific support and emotional calmness. Moreover, developing scientific and cognitive skills of mentees, nurturing positive identity in them $[3,6,8,17]$, and mentee development lead to the promotion of professional and emotional competency and self-respect, which in turn, results in the success of mentees.

In mentoring interactions, mentees have opportunities in order to continuously observe mentor's scientific and professional behaviors. This leads to facilitation and modification of the mentee's learning. Psychological and scientific support also strengthens previous learning and helps the student to manage challenges. According to Strauss et al. [18], successful mentoring were characterized by reciprocity, mutual respect, clear expectations, personal connection, and shared values.

The components of Islamic mentoring questionnaire, which is based on Islamic culture, are highly similar to other findings in the literature. Roll modeling, challenging, coaching, consulting, protection, and scientific networking have emerged as the significant aspects of mentoring. However, existing differences should not be neglected. For instance, in the current study, alongside of good temper are two of the emphatic components in Islamic studies. This component means 'don't be overbearing, have good behaviors, nice words and good debate' in mentoring. Among these subcomponents, overbearing has been only focused on international studies, for example in the National Science Academy of America, 1997, cited in Akili [19]. Similar situation exists in terms of other components, i.e., respect and attention. Among the emphasized subcomponents of this component, i.e., identifying and considering the mentees' characteristics, respecting mentee and intimacy in relations, only the last one has been explicitly confirmed in international studies $[3,8,9]$. In addition components such as openness [20], intellectuality, wisdom [9], and cognitive abilities [4] have been considered to be de- veloped for mentoring, which did not appear as independent themes in the current study.

In addition to the above mentioned cases, the evaluated components, in the form of nine components, were extracted from Islamic literature and texts. Natural difference of Islamic paradigm and the ruling academic field on the international scale, in terms of responding to the main questions about human nature and his education, in spite of general similarities considered in the confirmatory mentoring Islamic components based on previous studies, several differences in nature aroused between these two paradigms, which requires attention in the interpretation of the current study findings.

Vertical type of mentoring was also noticed in the current study. As Kram and Isabella [21] proposed many years ago, given two important components in mentoring, i.e., developing relations and experience, these relations can also occur horizontally between peers or inside a group situation.

The psychometric properties of designed questionnaire were also confirmed using a survey of experts, internal consistency, Cronbach's $\alpha$, content validity, and factor validity. However the other indicators of questionnaire validity such as concurrent and criterion validity have not been determined which can be the subject of future studies. Moreover, the results of the current study were obtained from the data collected from the students of medical sciences faculties. Its application in other situations requires evaluations, which other methods such as concurrent validity should be taken into account as well. Despite such limitations, the developed questionnaire generally seems to have required validity for measuring the mentoring relations.

In terms of the practical purposes and considering the importance of individuals being able to get to know each other and find compatibility in mentoring relationships, the significance of defining and classifying professional 
and expertise records of professors can help the students to choose the professors which are capable of meeting their needs. This leads to compatibility between the professors and students. Furthermore, the developed tool in the current study can be used for assessing and proposing feedback to professors and clarifying their weaknesses and strengths in mentoring and help them and their respective institutions to plan for overcoming their weaknesses. It can be also a basis for obtaining objective data with regard to the outputs of mentoring programs and assessing considerable levels of their effectiveness. Moreover, mentors and their mentees can potentially use the findings for further identifying each other and clarifying their disagreed points. Finally, they can identify their needs and expectations and adapt them with the needs, responsibilities and abilities of opposite party.

\section{ORCID:}

Morteza Khaghanizadeh: https://orcid.org/0000-0003-2404-2857; Husein taqavi: https://orcid.org/0000-0001-5943-8806; Abbas Ebadi: https://orcid.org/0000-0002-2911-7005

Acknowledgements: None.

Funding: No funding was received for this research.

Conflicts of interest: No potential conflict of interest relevant to this article was reported.

Author contributions: Conception or design of the work and data collection: MK, HT; analysis and interpretation of data for the work: MK, HT, AE; drafting the article, $\mathrm{MK}, \mathrm{HT}$; and critical revision of the article, and final approval of the version to be published: MK, HT, AE.

\section{References}

1. Wenger E. Communities of practice and social learning systems: the career of a concept. In: Blackmore C, ed. Social Learning Systems and Communities of Practice. London, UK: Springer; 2010:179-198.

2. Schunk DH. Learning theories: an educational perspective. 6th ed. Upper Saddle River, USA: Pearson; 2012.

3. Kram KE. Phases of the mentor relationship. Acad Manag J. 1983;26(4):608-625.

4. Johnson WB. A framework for conceptualizing competence to mentor. Ethics Behav. 2003;13(2):127-151.

5. Haggard DL, Dougherty TW, Turban DB, Wilbanks JE. Who is a mentor?: a review of evolving definitions and implications for research. J Manag. 201 1;37(1):280-304.

6. Grossman SC. Mentoring in nursing: a dynamic and collaborative process. New York, USA: Springer Publishing Company; 2013.

7. Ghosh R. Mentors providing challenge and support: integrating concepts from teacher mentoring in education and organizational mentoring in business. Hum Resour Dev Rev. 2013;12(2):144-176.

8. Noe RA. An investigation of the determinants of successful assigned mentoring relationships. Pers Psychol. 1988; 41(3):457-479.

9. Ackroyd R, Adamson KA. Mentoring for new consultants. J R Coll Physicians Edinb. 2015;45(2):143-147.

10. Fleming M, House S, Hanson VS, et al. The mentoring competency assessment: validation of a new instrument to evaluate skills of research mentors. Acad Med. 2013; 88(7):1002-1008.

11. Anderson L, Silet K, Fleming M. Evaluating and giving feedback to mentors: new evidence-based approaches. Clin Transl Sci. 2012;5(1):71-77.

12. Bazargan A. Introduction to qualitative and mixed research methods. Tehran, Iran: Didar: 2010.

13. Aveyard H. Doing a literature review in health and social care: a practical guide. 3rd ed. Maidenhead, UK: Open University Press, McGraw-Hill Education; 2014.

14. Hooman HA. Educational and psychological measure- 
ments. Tehran, Iran: Parsa; 2013.

15. Lynn MR. Determination and quantification of content validity. Nurs Res. 1986;35(6):382-385.

16. Lawshe $\mathrm{CH}$. A quantitative approach to content validity. Pers Psychol. 1975;28(4):563-575.

17. Sambunjak D, Straus SE, Marusić A. Mentoring in academic medicine: a systematic review. JAMA. 2006; 296(9):1103-1115.

18. Straus SE, Johnson MO, Marquez C, Feldman MD. Characteristics of successful and failed mentoring relationships: a qualitative study across two academic health centers. Acad Med. 2013;88(1):82-89.

19. Akili W. On mentoring relationships: how to become a good mentor. Paper presented at: 2013 IEEE Frontiers in Education Conference (FIE); October 23-26, 2013; Oklahoma City, OK, USA.

20. Perry RE, Parikh JR. Developing effective mentor-mentee relationships in radiology. J Am Coll Radiol. 2018;15(2): 328-333.

21. Kram KE, Isabella LA. Mentoring alternatives: the role of peer relationships in career development. Acad Manag J. 1985;28(1):110-132. 


\section{Appendix 1. Final Version of the Islamic Mentoring Questionnaire (IMQ)}

Please mark the option that is best suited for your relationship with your supervisor, after reading the items on the left.

Items $\quad$ Never Rarely Sometimes Often Always

1. I listen to and accept the supervisor's utterances attentively.

2. I accept the values respected by the supervisor as my own values.

3. I try to imitate him/her in scientific and professional matters and act out what he/she does.

4. I consider behaving humble before my supervisor as my honor and pride.

5. He/she feels closer to some of us and pays more attention.

6. He/she acts and is bound to the assertions and promises he/she makes.

7. He/she courageously expresses scientific truths with no censorship.

8. He/she is proficient in his/her scientific and expertise field and advances the actions related to our task in a wise manner.

9. He/she assigns me high-level homework and responsibilities through the accomplishment of which I learn things that will be useful for me when performing more difficult and important tasks.

10. He/she uses diverse methods to evaluate my status.

11. He/she assigns me tasks and duties that require extra effort to be accomplished.

12. He/she assigns me activities and homework, the accomplishment of which necessitates contemplation and pondering.

13. In every situation, he/she has full awareness of existing issues and opportunities and he/she informs me of them.

14. He/she broadens myperspective on what he/she has instructed me and, also, about the things I research such that the position of every problem and its relationship with other unknowns and knowns become somewhat clear to me.

15. He/she encourages me towards obtaining a performance on a higher level by illustrating the future position that I attempt to possess.

16. Constantly reminding me of the scientific position I am in, he/she makes me aware of the deviations and looseness that I might inflict with.

17. He/she shows me in practice what he/she wants to teach me.

18. He/she spends a sufficient amount of time to help me make up for my weak points.

19. He/she elaborates on the principles and guidelines through a clear-cut and documented method and helps me operationalize them.

20. He/she exposes me to important questions so as to guide me towards the goals of the task I am going to do (such as dissertation).

21. He/she is serious about presenting scientific materials and experiences and has a sense of duty.

22. He repeats the discussed matters for me when needed, without producing any negative reaction.

23. He/she programs the duties and tasks such that I can finish them on the due time.

24. He/she offers the materials and instructions in a hierarchical fashion, and based on a logical sequence (from 'most important' to 'least important' and 'easy to difficult')

25. He/she is earnest in what he/she is going to teach, and acts eagerly

26. He/she provides me with exact and clear recommendations in various forms Iwritten and orall for the purpose of my improvement in my assignments

27. He/she has specified particular times on any day of the week to discuss matters and negotiate with me.

28. He/she makes me interested in knowledge and university with his/her behavior and words.

29. He/she appreciates my scientific and research efforts in any opportunity that comes along. 
30. He/she encourages me to move beyond what I am now.

31. He/she encourages me at the right time and in a way that pleases me.

32. Any time I think I have performed well, he/she, too, transfers the same feeling to me with his/her words and behaviors.

33. When he/she praises or appreciates me, he/she shows why he/she is doing it.

34. He/she believes in the proverb that says "better to ask the way than go astray".

35. He/she generally accepts his/her mistakes and believes that not everyone is immune to making mistakes.

36. He/she treats my mistakes such that I can learn something from them.

37. He/she trusts me enough to assign me important tasks.

38. He/she encourages me to the comfortable expression of feelings and worries about which I prefer not to talk.

39. I ask him/her every question I think is necessary without worrying about questioning my qualifications and/or beliefs.

40. When I speak about my personal problems and concerns, he/she listens patiently and tolerantly.

41. He/she understands my weak and strong points and pays attention to them when offering feedbacks.

42. He/she reminds me of the positive points of my performance even when he/she is criticizing me.

43. He/she always has recommendations in his/her pocket for the improvement of personal behavior and the management of personal affairs.

44. With his/her words and behaviors, he/she helps me take important life issues (like familial and academic affairs, relationships, and marriage) seriously.

45. He/she is always available when I need him/her Ivia telephone, email, in person, and ...l

46. He/she shows me with his/her behaviors that I can count on his/her help.

47. He/she helps me solve my personal problems and issues (nonacademic) as much as he/she can.

48. He/she allows me to operationalize my ideas and notions.

49. He/she modifies his/her programs and decisions after hearing my opinions.

50. He/she provides me with feedback and recommendations proportionate to my scientific and expertise level.

51. He/she shares his/her experiences and adventures with me in a manner related to my problems.

52. He/she arranges his/her recommendations in proportion to my needs.

53. He/she spends time with me through conversation and extra-curricular and research activities.

54. He/she tries to be aware of my status one way or another.

55. There is a permanent and continuous relationship between me and my supervisor.

56. He/she knows me and other students by name and specifications.

57. He/she does everything in his/her power to facilitate existing conditions.

58. If he/she happens to ask me a question I cannot answer, he/she behaves reproachfully.

59. He/she treats me courteously and nobly.

60. He/she is considerate and thoughtful in his/her daily behaviors

61. He/she occassionally uses inappropriate and incorrect words in his/her utterances.

62. His/her words are fascinating and influential.

63. He/she tries to prove that he/she is right, no matter what it takes.

64. He/she permits discussion on cases we have no agreement. 
65. When a discussion or debate occurs about a subject, he/she advances it in an appropriate method and without harming my feelings of competency, beliefs, and values.

66 . He/she values participation and cooperation in problem-solving and encourages me to cooperate with others.

67. He/she sets the conditions so that I can learn to contribute to others.

68. He/she puts me in situations wherein I can discuss things with the experts in my study field.

69. He/she introduces me to masters and experts if required.

70. He/she assigns me homework the doing of which can develop my communication skills (for interaction with experts).

Appendix 2. Islamic Mentoring Questionnaire (IMO) Components and Related Items

\begin{tabular}{ll}
\hline \multicolumn{1}{c}{ Components } & Item \\
\hline Role modeling & $1-8$ \\
Challenging & $9-16$ \\
Coaching & $17-27$ \\
Encouragement & $28-33$ \\
Counseling & $34-42$ \\
Protecting & $43-47$ \\
Care \& reverence & $48-56$ \\
Facilitating & $57-65$ \\
Scientific networking & $66-70$ \\
Reverse score items & $5-58-61-63$ \\
\hline
\end{tabular}

